\title{
Effect of curriculum changes to enhance generic skills proficiency of 1 st-year medical students
}

\author{
D Murdoch-Eaton, ${ }^{1}$ MBBS, MD, FRCPCH; A J N Louw, ${ }^{2}$ BEd, MEd, PhD; J Bezuidenhout ${ }^{2}$ MB ChB, MMed, PhD
}

${ }^{1}$ Medical Education, Medical School, University of Sheffield, UK

${ }^{2}$ Centre for Health Professions Education, Stellenbosch University, Cape Town, South Africa

Corresponding author: A J N Louw(ajnlouw@sun.ac.za)

\begin{abstract}
Background. Curriculum review is a dynamic, iterative process, and the effect of change may not always be wholly predictable. At Stellenbosch University, Cape Town, South Africa, revision of the $\mathrm{MB}, \mathrm{ChB}$ curriculum was undertaken to meet enhanced and changing educational and medical practice, and to provide opportunities to enhance optimal generic skills underpinning effective learning, implemented in 2008.

Objective. To determine the extent to which the newly implemented revised curriculum had an effect on experience in necessary generic skills of students in their first year of study.

Methods. Students provided annual formal end-of-module evaluation in addition to focus group interviews. Evaluation by teaching staff was conducted by individual in-depth interviews. A validated generic skills questionnaire completed at the end of each academic year monitored the effect on students' generic learning skills experience.

Results. Feedback from these different evaluation methods identified specific needs in the newly implemented revised curriculum, including contextualisation of interventions, unnecessary duplication of content and malalignment of assessment. This led to minor curriculum changes and an educational capacity-building programme. These responsive curriculum changes after evaluation had the intended positive effect on students' selfreported acquisition of generic learning skills.

Conclusion. The objective of the curriculum evaluation was to monitor content output and the acquisition of crucial generic learning skills. Implementation of a revised curriculum combined with ongoing responsive changes aligned with careful multimodality evaluation can ensure that, in addition to scientific knowledge and skills, generic learning skills development of students is facilitated.
\end{abstract}

Afr J Health Professions Educ 2016;8(1):15-19. DOI:10.7196/AJHPE.2016.v8i1.414

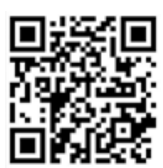

In a constantly and rapidly changing environment, the training of competent, caring and committed healthcare professionals requires a continuous cycle of curriculum revision, implementation and evaluation. This is crucial to keep up to date with changes in educational practice and advances in medical knowledge. Society expects that medical graduates function as healthcare change agents. ${ }^{[1]}$

There is an increasing awareness of the centrality of generic learning skills underpinning success at university and fostering effective life-long learning. ${ }^{[2]}$ Many higher educational courses have introduced explicit generic skills training in their programmes to ensure that these skills are embedded early. ${ }^{[3]}$

Globally, school curricula strive to ensure that such skills are introduced. It is recognised that students are most vulnerable during the crucial transition period from high school to university. ${ }^{[4]}$ The skills profiles of medical entrants are not static; Whittle et al. ${ }^{[5]}$ identified a changing profile of the key skills that underpin learning. Furthermore, a widening access agenda means that students come from a diverse range of educational backgrounds, some of which almost certainly mean that the students are potentially educationally disadvantaged. ${ }^{[6]}$

This necessitates sufficient support within a curriculum designed to ensure knowledge and skills acquisition relevant to the course, and identifies and addresses deficiencies in students' learning and other generic skills. Curricula need to ensure incorporation of opportunities to practise these skills, and importantly for students, to obtain feedback. ${ }^{[2,6]}$

Comprehensive evaluation is essential to understand the effect of the curriculum, including aspects introduced specifically for generic learning skills acquisition. These should include review of the needs of students, ensuring that the necessary generic capabilities and sufficient practice are provided. ${ }^{[7]}$ This requires a regular, cyclical process of curriculum evaluation, especially after significant change, to allow embedding and re-evaluation of whether the desired effect has been achieved and further changes are needed.

The purpose of this study was to evaluate the effect of a newly revised curriculum, including the acquisition of generic skills underpinning effective learning, on 1st-year students at the Faculty of Medicine and Health Sciences (FMHS), Stellenbosch University (SU), Cape Town, South Africa (SA).

\section{Methods \\ Context}

The study population consisted of all 1st-year medical students at the FMHS, SU from 2007 to 2011.

Major curriculum revisions were undertaken in the early years of the 6-year MB,ChB programme and implemented from the beginning of 2008 (Table 1). The main purpose of the revision was to introduce - in the first semester after arrival at university - curriculum elements focusing on a combination of generic skills and basic practice skills integrated within the sciences in an interdisciplinary, SA medical education context. Modules emphasised generic skills, i.e. that students need not only succeed in their studies, but also be responsible professionals. These skills comprise inter alia academic literacy, acquisition of an additional language, stress management, study skills, and how these are relevant in the context of ethics, professionalism, biostatistics, epistemology, and interdisciplinary behaviour. 
Table 1. Summary of medical curriculum changes during the study period

\begin{tabular}{|c|c|c|c|c|c|}
\hline & 2007 & 2008 & 2009 & 2010 & 2011 \\
\hline $\begin{array}{l}\text { First-semester } \\
\text { modules }\end{array}$ & $\begin{array}{l}\text { Chemistry } \\
\text { Biology } \\
\text { Data management } \\
\text { Physics }\end{array}$ & $\begin{array}{l}\text { Chemistry for health } \\
\text { sciences } \\
\text { Personal and } \\
\text { professional } \\
\text { development } \\
\text { Health in context } \\
\text { Life forms and } \\
\text { functions of clinical } \\
\text { importance }\end{array}$ & $\begin{array}{l}\text { Chemistry for health } \\
\text { sciences } \\
\text { Personal and professional } \\
\text { development } \\
\text { Health in context } \\
\text { Life forms and functions } \\
\text { of clinical importance }\end{array}$ & $\begin{array}{l}\text { Chemistry for health sciences } \\
\text { Personal and professional } \\
\text { development } \\
\text { Health in context } \\
\text { Life forms and functions of } \\
\text { clinical importance }\end{array}$ & $\begin{array}{l}\text { Chemistry for health } \\
\text { sciences } \\
\text { Personal and } \\
\text { professional } \\
\text { development } \\
\text { Health in context } \\
\text { Life forms and functions } \\
\text { of clinical importance }\end{array}$ \\
\hline $\begin{array}{l}\text { Second-semester } \\
\text { modules }\end{array}$ & $\begin{array}{l}\text { Cell and tissue } \\
\text { haematology and } \\
\text { immunology } \\
\text { Respiratory system } \\
\text { Cardiovascular system } \\
\text { Ethics }\end{array}$ & $\begin{array}{l}\text { Essentials of disease } \\
\text { processes } \\
\text { Principles of therapy }\end{array}$ & $\begin{array}{l}\text { Essentials of disease } \\
\text { processes } \\
\text { Principles of therapy }\end{array}$ & $\begin{array}{l}\text { Essentials of disease processes } \\
\text { Principles of therapy } \\
\text { Introduction to clinical } \\
\text { medicine }\end{array}$ & $\begin{array}{l}\text { Essentials of disease } \\
\text { processes } \\
\text { Principles of therapy } \\
\text { Introduction to clinical } \\
\text { medicine }\end{array}$ \\
\hline $\begin{array}{l}\text { Significant } \\
\text { changes }\end{array}$ & & $\begin{array}{l}\text { Position natural } \\
\text { sciences in a health } \\
\text { context } \\
\text { Reduce science content } \\
\text { Introduce two generic } \\
\text { skills modules } \\
\text { Replace systemic } \\
\text { modules in second } \\
\text { semester with } \\
\text { basic principles of } \\
\text { pathological and } \\
\text { therapeutic processes }\end{array}$ & $\begin{array}{l}\text { Reduce content overlap } \\
\text { and duplication between } \\
\text { modules } \\
\text { Decrease number of } \\
\text { lectures } \\
\text { Emphasise contextualising } \\
\text { of modules within the } \\
\text { health sciences } \\
\text { Improve quality of study } \\
\text { guides } \\
\text { Change to continuous } \\
\text { assessment in two of the } \\
\text { first-semester modules }\end{array}$ & $\begin{array}{l}\text { Restructure and contextualise } \\
\text { chemistry for health sciences } \\
\text { Implement computer skills } \\
\text { training } \\
\text { Contextualise assessments } \\
\text { across modules (horizontal } \\
\text { integration) } \\
\text { Dedicated time slots for } \\
\text { teamwork } \\
\text { Implement introduction to } \\
\text { clinical medicine module } \\
\text { Staff changes and capacity- } \\
\text { building short courses }\end{array}$ & $\begin{array}{l}\text { Minor refinements in all } \\
\text { modules }\end{array}$ \\
\hline
\end{tabular}

\section{Curriculum evaluation}

Formal end-of-module evaluation by students was undertaken using a standard questionnaire, including closed questions (a 3-point Likert scale) and open-ended questions. Additionally, two focus group discussions (FGDs) were conducted annually (end of first and second semesters; 8 - 10 students per FGD). Teaching staff conducted evaluation by individual in-depth interviews (IDIs).

At the end of 2008, an accreditation visit by the Health Professions Council South Africa (HPCSA) provided external evaluation.

\section{Generic skills evaluation}

The effect of the students' generic learning skills experience was monitored using a validated generic skills questionnaire completed at the end of each academic year. ${ }^{[8]}$ Students rated their frequency of practice $(1=$ never, to $4=$ every week) of 31 key generic skills, grouped into six categories, i.e. information handling, technical and numeracy, information technology (IT), time management, managing own learning and presentation skills (Table 2). The questionnaire has been validated and shown to be reliable in the SA context, with stability of items within the skills categories verified by factor analysis. ${ }^{[9]}$ Data were analysed with the Statistical Package for the Social Sciences (SPSS) 17 (USA), using analysis of variance (ANOVA) to investigate differences between year groups.

While the generic skills questionnaire includes evaluation of confidence, for the purpose of this curriculum experience study the emphasis was on practice. The generic skills profile of students entering SA medical schools, including $\mathrm{SU}$, over the period of this study, seems according to studies in progress not to be significantly different across and within institutions.

\section{Ethical approval}

Ethical approval was obtained from the Human Research Ethics Committee, FMHS, SU (N07/03/05). Informed consent was obtained from all the participants before participation in the study.

\section{Results}

Enrolment ranged from 230 students in 2007 to 264 in 2011 (total number of students over the 5 years: 1 161). Eighty-five percent were firsttime students (direct entrants) aged 18 years, the remainder having undertaken prior graduate studies. The ethnic diversity of the population did not alter significantly over the study period.

\section{Curriculum evaluation and modifications}

A comprehensive semester evaluation report is compiled annually, including key aspects of good practice, in addition to areas of concern identified from student and staff feedback, and was used to inform minor curriculum interventions in 2009, which required immediate implementation. Full impact evaluation over 2 years informed more substantive curricular change, implemented in 2010 (Table 1).

\section{Contextualisation, alignment and assessment}

From the FGDs it emerged that students were not satisfied with the relevance of the modules with regard to their future professions and considered that assessments were not wholly aligned with outcomes. 
Table 2. Thirty-two generic skills evaluated by the questionnaire, grouped into six main categories ${ }^{[8]}$

\begin{tabular}{ll}
\hline Categories & Skills \\
\hline Information handling & Researching a new topic using library \\
& resources \\
& Selecting information \\
& Interpreting information \\
& Using information to solve problems or \\
& answer questions \\
Technical and numeracy skills & Performing laboratory experiments \\
& Designing your own experiments \\
& Analysing experimental data, e.g. graphs \\
& Drawing conclusions from your data \\
& Calculations \\
& Statistics \\
& Word processing \\
& Spreadsheets \\
& Databases \\
IT skills & Using the internet to find information \\
& Using email \\
& Managing your time/meeting deadlines \\
& Planning tasks \\
& Thoroughness/accuracy \\
Presentation skills & Teamwork \\
Organisational skills & Coping with stress \\
& Learning from other students \\
& Receiving feedback positively \\
& Giving constructive feedback \\
& Taking responsibility for your own learning \\
& Evaluating your strengths and weaknesses \\
& Essay writing \\
& Writing laboratory reports \\
& Explaining ideas \\
& Giving oral presentations \\
& Communicating with other scientists/doctors \\
& Communicating scientific/medical ideas to \\
& non-scientists \\
& \\
Managing your own learning & \\
&
\end{tabular}

'It doesn't make sense! It feels if we learn nothing, and nothing is applicable to us ... the testing is dumb. Parrot learning teaches you very little and all these assessments required parrot learning instead of application of knowledge.' (FGD10B St4 2008)

'There are too many themes that waste our time' and '... the relevance of some parts of this work was not clear to me.' (FGD1 St3 2009)

'... generally it's been said that they [students] feel like some of the modules are useless because we are focusing on the main thing that we are here for, and that is medicine.' (FGD10 St5 2008)

Students' comments during FGDs and the formal module feedback at the end of each module contributed to recognition of a need for several changes. The key interventions focused around improving the contextualising topics, especially chemistry and generic learning skills; alignment of assessment and outcomes; use of integrated single assignments to assess more than one theme; and change from end-of-semester to continuous assessment in two modules.

Methods for enhanced contextualisation included starting the semester with role-play by teaching staff and senior faculty management demonstrating the relevance of all four modules, followed by small group discussions and a debriefing, an explanation at the start of each theme of the relevance of that specific theme, and the continuous use of real-life examples.

\section{Curriculum mapping}

Reducing overlap, fostering integration, and eliminating conflicting messages reflected in the study guides were at the heart of curriculum mapping interventions. Prior to the curriculum interventions students commented:

'Some content between the modules and different themes overlap and repeats.' (FGD5 St5 2009)

'The themes in the module were very random and the information wasn't continuous and it was frequently repeated and didn't seem relevant.' (FGD8 St7 2009)

\section{Educational capacity development}

The need for educational capacity development was illustrated by the following quote from a module chair:

'Some lecturers feel overwhelmed by large class groups and experienced it as dominating. (IDI3)

Some students felt as follows:

'... the lecturers I think can still be a bit more interactive with us, and not just stand there and do their lecture slides.' (FGD1 St4 2009)

This was echoed by other teaching staff and resulted in the development and implementation of a very successful short course on interactive teaching, with an emphasis on large classes.

\section{HPCSA evaluation}

In 2008 the external evaluation panel of the HPCSA highlighted a number of positive aspects of the newly implemented 1st-year curriculum: the interdisiplinary nature of this phase was commended, especially as it does not exist elsewhere in SA; the emphasis on teamwork and establishing the concept of a health team in the first year; the development of communications skills, stress management and academic literacy; and the use of case studies on the 'Essentials of disease processes' module in the second semester.

Recommendations were made to improve the extent of integration of content in the four modules, align assessment with outcomes, and be vigilent for 'content overload'.

\section{Generic skills evaluation}

Responses were obtained from 1002 students at the end of each academic year over the study period ( $86.2 \%$ response rate).

The new curriculum, from implementation in 2008, showed a sustained and positive effect on students' practice in information handling skills (Fig. 1). Technical and numeracy skills, however, initially showed a negative effect, with significantly reduced reported practice; curriculum changes implemented in 2010 in response to this led to a reversal. Similarly, 


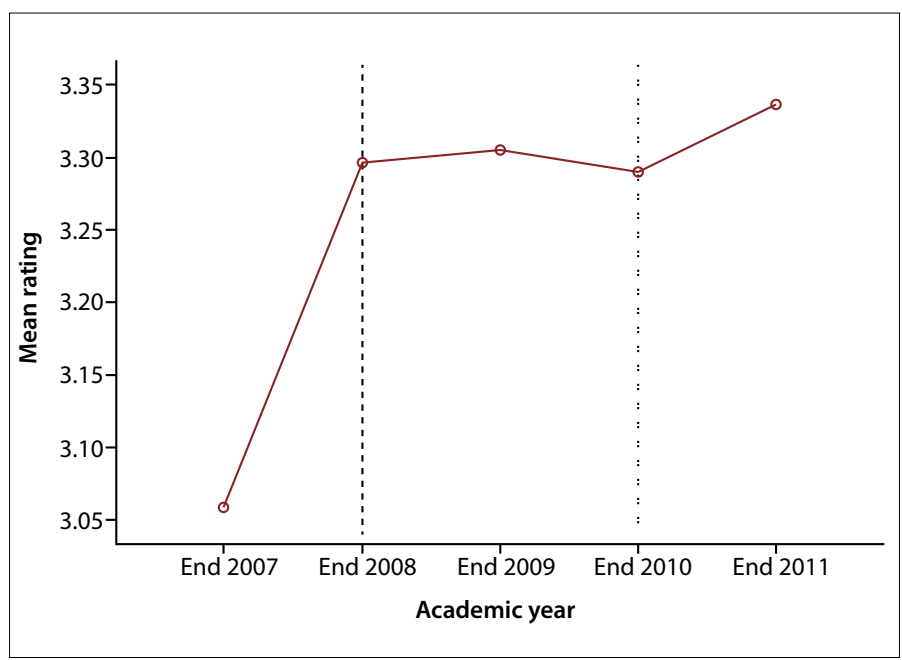

Fig. 1. Information-handling skills (practice).

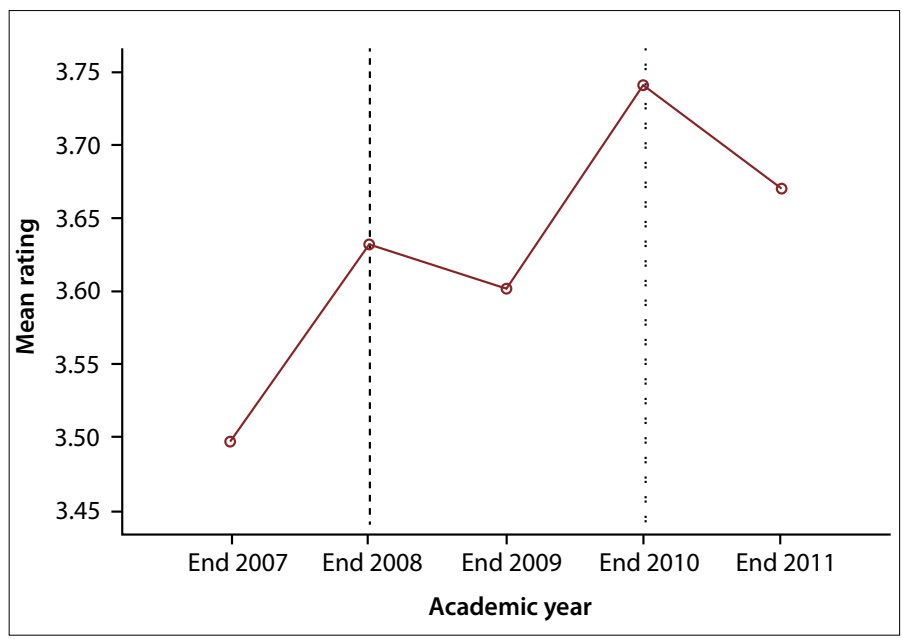

Fig. 3. Organisational skills (practice).

significantly enhanced information technology skills, managing own learning skills and organisational skills practice were only reported from 2010 (Figs 2 - 4). No effect was identified with presentation skills practice. Interventions in the individual curriculum changes that contributed to enhanced practice are illustrated in Table 1.

\section{Discussion}

Curriculum review is a dynamic, iterative process and the effect of change may not always be entirely predictable. Curriculum content and process should be continually reviewed, recognising that the student population changes and that delivery is influenced by a multitude of factors ranging from the educational environment through to teachers. Bitzer ${ }^{[10]}$ highlights that a curriculum must maintain relevance in the context of societal, university and student changes, and to improve it must be evaluated regularly. The evaluation process at $\mathrm{SU}$ is strengthened by a formal annual process of module evaluation, including both student and teaching staff perceptions.

This study is additionally strengthened by information provided by the generic skills practice evaluation, which collectively contributed to a responsive curriculum review evaluation, resulting in appropriate and responsive considered interventions ${ }^{[8]}$ Evidence of enhanced skills around

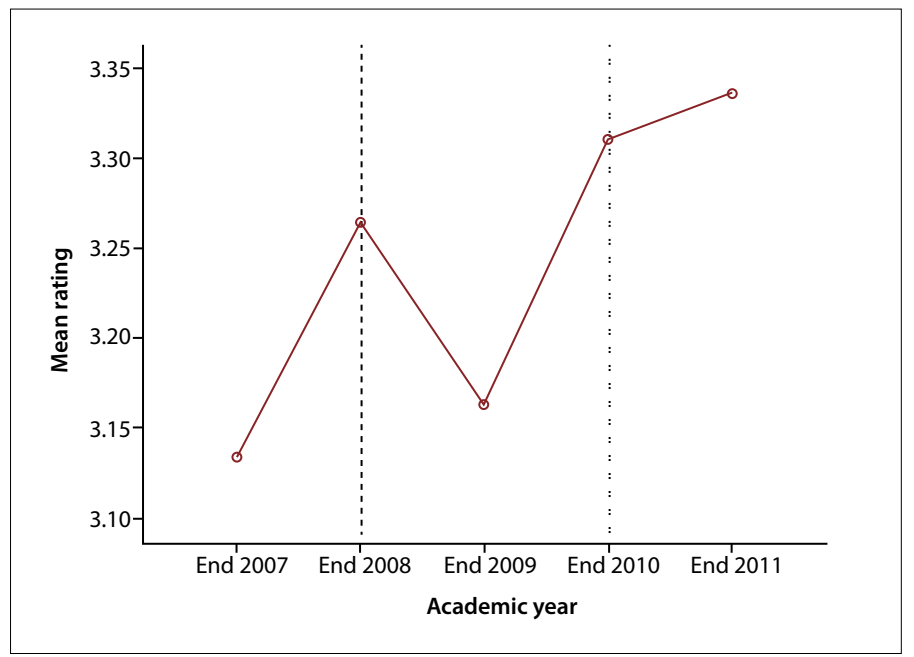

Fig. 2. Information technology skills (practice).

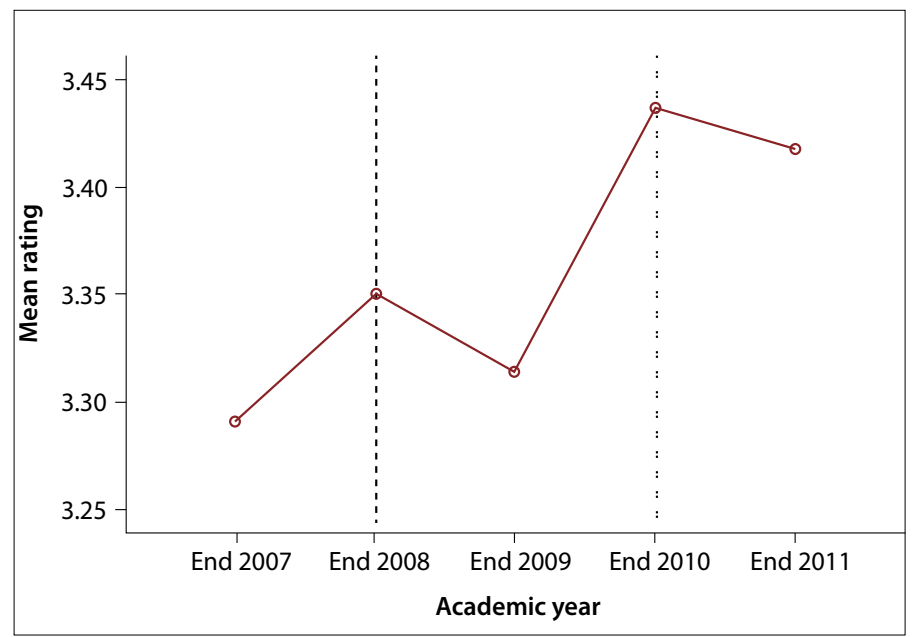

Fig. 4. Managing own learning skills (practice).

'Managing your own learning' underpins much of the intended curriculum effect, initially introduced in 2008 and reinforced in 2010.

The effect of changes in assessment approach on students' learning is well recognised. ${ }^{[11]}$ Assessment changes in the curriculum review included enhanced alignment with learning outcomes, identifying clearly for students the importance of skills and content, e.g. around application of academic literacy. Some significant increases in the generic skills practice level, especially from 2010, indicate the influence of a change to continuous assessment in the modules that particularly require generic learning skills around information handling (academic literacy), technical and numeracy (statistics), IT skills (word processing and spreadsheets) and organisational skills.

One particularly significant intervention was recognised as being necessary after consideration of the 2008 and 2009 curriculum evaluation results, including feedback from students and review of teaching staff interviews, i.e. the full effect on student learning had not been realised. Enhancement of teaching skills was clearly identified as an area of particular need to fully implement the intended curriculum changes. A programme of staff development was therefore implemented before the start of 2010. The subsequent effect on students' generic learning skills 
experience was evidenced by further enhancement of skills practice in 2010 and 2011.

The sustained increase in information handling skills practice reflected the new curriculum requirement for participation in 'research' from admission. The revised course required students to actively use and identify a range of resources to select, interpret and apply information to problem solving. These include diverse activities ranging from, e.g. interviewing people to gain information, to reading up on topics, through to a more scientific enquiry from conventional written texts. Moreover, the increase in experience was also driven by a continuous process of formative and summative assessments and feedback, including assignments, presentations and online quizzes. ${ }^{[7]}$

The initial reported reduction in practice in technical and numeracy skills in 2008 and 2009, followed by an improvement with an increase in experience in these skills in 2010 and 2011, is interesting. This is an example of a potentially unintended consequence of curriculum changes and why monitoring of skills practice crucially contributed to the curriculum evaluation. The changes can be explained by the removal of physics as a pure scientific module in the first year, and the down-scaling of biostatistics in the new revised curriculum. Curriculum interventions subsequently introduced included contextualisation and redesign of modules (such as chemistry and biostatistics), which might account for the enhanced reported practice from 2010. No single intervention is likely to wholly account for the enhanced skills, which illustrates the value of integrated, collaborative discussion of multiple sources of evidence and feedback.

The World Federation for Medical Education identified a minimum basic standard for effective use of e-learning skills during training. An often-made assumption is that all students have sufficient practice in IT skills during their high-school years. ${ }^{[5]}$ In SA, however, it is possible that some students enrolling at universities lack these skills. ${ }^{[12]}$ As part of the curriculum monitoring, students and staff indicated a potential deficiency in IT skills in some 1st-year students. The implementation in 2010 of a specific IT intervention may be interpreted as the reason for the resulting reported increase in IT skills.

There has been an increasing trend in the level of experience of students' organisational skills since 2008, but a definite and significant positive change occurred in 2010 and 2011. Organisational skills include aspects of self-management, such as meeting deadlines. To meet deadlines, students have to plan and manage their time. From 2010, two of the modules used continuous assessment, which required students to take responsibility for managing different assignments and tasks on a variety of topics, some involving teamwork and meeting different submission dates. Students therefore have to learn to work in a group, and learn from, receive and give feedback to one another. While working in a team, students evaluate their own strengths and weaknesses, and soon realise the important role of each individual group member for the group to function optimally. ${ }^{[13]}$ This method of teaching and assessing students forced them to take responsibility for their own learning, which consequently had an effect on students' 'Managing your own learning skills', evidenced by the positive, sustained enhanced practice in this skill. These skills are important for success in high-pressure environments, particularly for later success at university, and subsequent future medical practice.

It is also possible that other areas of change management, including enhanced staff communication, engagement with collaborative decision- making (at all levels - from administrative support staff to teaching staff), scrutinising study guides to enhance transparency, and other subtle changes in approach that are difficult to measure and articulate, are almost certainly cumulative and contributory. This approach to curriculum review reinforces the importance of a scholarly approach to all aspects of educational practice, and aligns with Van der Vleuten's appeal that educational research, which informs practice, should be evidence based. ${ }^{[14]}$

\section{Conclusion}

Contextual skills development in medicine is vital and more effective when embedded in the curriculum. This underpins the approach taken in this curriculum review, ensuring that key generic learning skills are addressed. Our study indicates the value of curriculum evaluation that goes beyond monitoring output only in terms of content outcomes. It also evaluated the effect on student learning, specifically how they are equipped with generic learning skills to support their expected success at university. Such a comprehensive methodological approach not only takes into account feedback and evaluation from staff and students, but, importantly, evaluates effect, particularly on skills development. This ensures identification of how the curriculum meets the diversity of learning needs and skills present on entry into higher education.

\section{Practice points}

- Scientific research is a tool to evaluate a curriculum and enhance the validity of the evaluation process, and results in appropriate and responsive considered interventions.

- Change to the type of assessments results in significant increased changes to the generic skills practice levels of students.

- Curriculum changes have to be accompanied by the necessary and appropriate staff development initiatives.

- Key generic skills have to be embedded in a curriculum, and the contributions of the curriculum have to support student success by means of methodological evaluation processes.

References

1. Frenk J, Chen L, Bhutta ZA, et al. Health professionals for a new century: Transforming education to strengthen health systems in an interdependent world. Lancet 2010;376:1923-1958. [http://dx.doi.org/10.1016/S01406736(10)61854-5]

2. Murdoch-Eaton DG, Whittle S. Generic skills in medical education: Developing the tools for successful lifelong learning. Med Educ 2012;46:120-128. [http://dx.doi:org/10.1111/j.1365-2923.2011.04065.x]

3. Barrie S. A conceptual framework for the teaching and learning of generic graduate attributes. Studies in Highe Education 2007;32:439-458. [http://dx.doi.org/10.1080/03075070701476100]

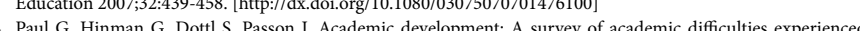
4. Paul G, Hinman G, Dottl S, Passon J. Academic development: A survey of academic difficulties experienced
by medical students and support services provided. Teach Learn Med 2009;21:254-260. [http://dx.doi. org $/ 10.1080 / 10401330903021041]$

5. Whittle SR, Pell G, Murdoch-Eaton DG. Recent changes to students' perceptions of their key skills on Whittle SR, Pell G, Murdoch-Eaton DG. Recent changes to students' perceptions of their key skills on
entry to higher education. J Further Higher Educ 2010;34:557-570. [http://dx.doi.org/10.1080/030987 entry to higher
7X.2010.512082]

7X.2010.512082]
6. Burch VC, Sikakana CNT, Gunston G, Shamley DR, Murdoch-Eaton D. Generic learning skills in academicallyat-risk medical students: A development programme bridges the gap. Med Teach 2013;35:671-677. [http://dx.do org/10.3109/0142159X.2013.801551]

7. Kember D. 2009. Nurturing generic capabilities through a teaching and learning environment which provides practice in their use. Higher Educ 2009;57:37-55. [http://dx.doi.org/10.1007/s10734-008-9131-7]

. Whittle SR, Murdoch-Eaton DG. Curriculum 2000: Have changes in sixth-form curricula affected students' key skills? J Further Higher Educ 2005;29:61-71. [http://dx.doi.org/10.1080/03098770500037762]

9. Murdoch-Eaton D, Manning D, Kwizera E, Burch V, Pell G Whittle S. Profiling undergraduates' generic learning skills on entry to medical school: An international study. Med Teach 2012:34:1033-1046. [http///dx doi.org/10.3 109/0142159X 2012 706338]

10. Bitzer E. First-year students' perceptions of generic skills competence and academic performance: A case study at one university. S Afr J Higher Educ 2005;19(3):172-187. [http://dx.doi.org/10.4314/sajhe.v19i3.25512]

11. Cilliers F, Schuwirth LWT, Herman N, Adendorff HJ, van der Vleuten CPM. A model of the pre-assessment learning effects of summative assessment in medical education. Adv Health Science Educ 2012;17:39-53. [http:// learning effects of summative assessment in medical education. Adv Health Science Educ 2012;17:39-53. [http:// dx.doi.org/10.1007/s10459-011-9292-5

12. Boveé C, Voogt J, Meelissen M. Computer attitudes of primary and secondary students in South Africa. Computers Human Behav 2007;23:1762-1776. [http://dx.doi.org/10.1016/j.chb.2005.10.004]

13. Hrynchak P, Batty H. The educational theory basis of team-based learning. Med Teach 2012;34:796-801. [http:// dx.doi.org/10.3109/0142159X.2012.687120]

14. Fincher RME, Simpson DE, Mennin SP, et al. Scholarship in teaching: An imperative for the 21st century. Acad Med 2000;75:887-894. 